\title{
Electrical Conductivity of 7,7,8,8-Tetracyanoquinodimethane Salts with Polycations Containing Sulfur Atoms and Aromatic Rings in the Main Chain
}

\author{
J. PECHERZ and M. KRYSZEWSKI \\ Centre of Molecular and Macromolecular Studies Polish \\ Academy of Sciences, 90-364 Lódź, Poland
}

(Received July 30, 1982)

\begin{abstract}
Electrical properties of complex anion radical salts of 7,7,8,8-tetracyanoquinodimethane (TCNQ) with polycations of the following structure:

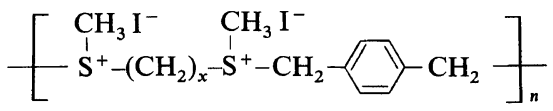

were investigated. It was found that the resistivity of simple salts increases linearly with an increase in the distance between positively charged donor centres $\mathrm{S}^{+}$. For complex salts, the increase in the distance between $\mathrm{S}^{+}$atoms results in an increase in electrical conductivity up to $x=6$. The lowest resistivity $\rho_{25}=3.11 \Omega \mathrm{cm}^{-1}$ and thermal lowest activation energy value $E_{\mathrm{a}}=0.021 \mathrm{eV}$ were found for complexes with $x=6$ and the ratio $\mathrm{TCNQ}^{\circ} / \mathrm{TCNQ}^{-}=1.0$. High conductivity values determined for these salts are related to the high polarizability of the polymeric cations.
\end{abstract}

KEY WORDS Semiconducting Polymers / Polysulfides / Polycation-

7,7,8,8-Tetracyanoquinodimethane Salt / Simple Salt / Complex Salt /

Doping / Polarizability of Cation /

Salts of 7,7',8,8'-tetracyanoquinodimethane (TCNQ) with polycation are well known organic semiconductors. ${ }^{1}$ Various papers have dealt with the analysis of the properties of complex TCNQ salts with ionenes containing methylene groups between quartenary nitrogen atoms $\mathrm{s}^{2-7}$ and polycations with different heterocyclic groups. ${ }^{8-14}$ The magnetic and optical properties of these substances have also been investigated; however, the crystalline structure of these salts is not known. In the case of low molecular weight salts, the stacks of neutral $\mathrm{TCNQ}^{\circ}$ and anion radicals $\mathrm{TCNQ}^{-}$are responsible for high electrical conductivity. ${ }^{17}$ In polymeric salts, the distance between the charged centers define the stack formation which may possibly thus influence electrical properties. Our recent papers ${ }^{18,19}$ describe the electrical behaviour of TCNQ complexes forward polycations containing positively charged $\mathrm{S}^{+}$ atoms separated by different numbers of $\mathrm{CH}_{2}$ groups. In this work, a continuation of our previous studies, we investigate polycations containing $\mathrm{CH}_{2}$ groups and aromatic moieties between positively charged sulfur atoms. The influence of the chemical structure of polycations on the electrical properties of obtained salts and complex salts of TCNQ was investigated, taking into considerations the relation of cation polarizability to the electrical conductivity of theses substances.

\section{EXPERIMENTAL}

\section{Monomer Syntheses}

$p$-Xylene was reacted with bromine to give 1,4bis(dibromomethyl)benzene. Aliphatic dithiols: 1,3propanedithiol, 1,4-butanedithiol, 1,5-pentanedithiol, 1,6-hexanedithiol, and 1,10-decanedithiol were purified by distillation.

\section{Preparation of Polysulfides and Polycations}

Polysulfides of the general formula

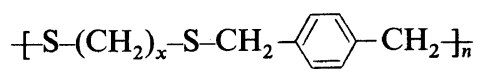




\section{J. PeChERZ and M. KRYSZEWSKI}

Table I. Synthesis of polysulfides ${ }^{\mathrm{a}}$

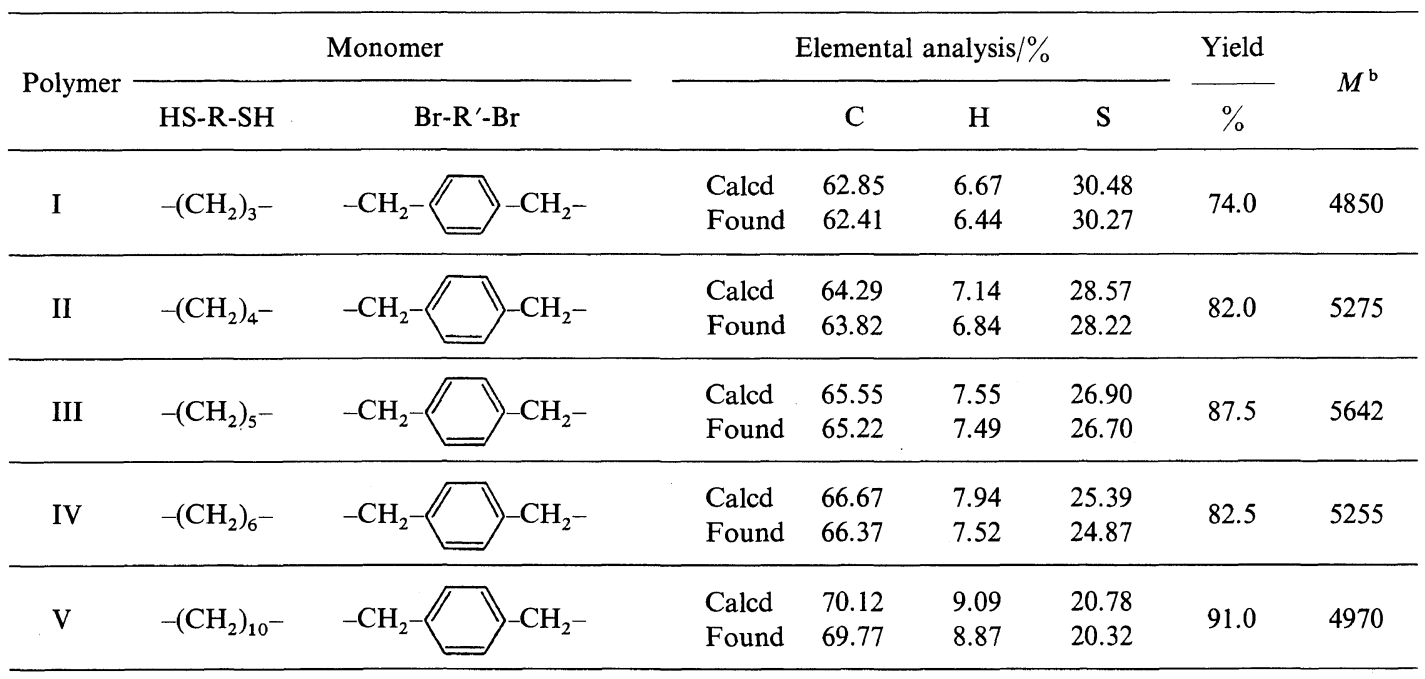

a Polymerization was carried out using equimolar amounts of monomers; $1.25 \times 10^{-2}$ mol; $2.5 \mathrm{~g}$ PEG-2000 in $12.5 \mathrm{ml}$ acetonitrile and $25 \mathrm{ml} 1.01 \mathrm{~N}$ of water solution of $\mathrm{KOH}$. Reaction time $24 \mathrm{~h}$ at $80^{\circ} \mathrm{C}$.

b Molecular weights of polymers were determined by a vapour pressure osmometer at $35^{\circ} \mathrm{C}$ in chloroform.

Table II. Synthesis of polycations ${ }^{\mathrm{a}}$

\begin{tabular}{|c|c|c|c|c|c|c|c|c|c|c|}
\hline \multirow{2}{*}{ Polycation } & \multirow{2}{*}{$\begin{array}{c}\begin{array}{c}\text { Concentration } \\
\text { of polysulfides }\end{array} \\
\text { moll }^{-1}\end{array}$} & \multirow{2}{*}{$\frac{\text { Solvent }}{\mathrm{CH}_{3} \mathrm{NO}_{2} / \mathrm{CHCl}_{3}}$} & \multirow{2}{*}{$\frac{\text { Time }}{\mathrm{h}}$} & \multirow{2}{*}{$\frac{\begin{array}{c}\text { Substitution } \\
\text { degree }\end{array}}{\%}$} & \multicolumn{5}{|c|}{ Elemental analysis $/ \%$} & \multirow{2}{*}{$\frac{\text { Yield }}{\%}$} \\
\hline & & & & & & $\mathrm{C}$ & $\mathrm{H}$ & $\mathrm{S}$ & I & \\
\hline$P_{\mathrm{s}}[3, \mathrm{Ar}]$ & 0.059 & $1 / 1$ & 20 & 98.5 & $\begin{array}{l}\text { Calcd } \\
\text { Found }\end{array}$ & $\begin{array}{l}31.60 \\
31.07\end{array}$ & $\begin{array}{l}4.10 \\
3.82\end{array}$ & $\begin{array}{l}12.96 \\
12.66\end{array}$ & $\begin{array}{l}51.44 \\
50.85\end{array}$ & 92.0 \\
\hline$P_{\mathrm{s}}[4, \mathrm{Ar}]$ & 0.035 & $1 / 1$ & 16 & 99.0 & $\begin{array}{l}\text { Calcd } \\
\text { Found }\end{array}$ & $\begin{array}{l}33.07 \\
32.29\end{array}$ & $\begin{array}{l}4.33 \\
4.11\end{array}$ & $\begin{array}{l}12.60 \\
12.35\end{array}$ & $\begin{array}{l}50.00 \\
49.05\end{array}$ & 95.0 \\
\hline$P_{\mathrm{s}}[5, \mathrm{Ar}]$ & 0.044 & $1 / 1$ & 20 & 98.5 & $\begin{array}{l}\text { Calcd } \\
\text { Found }\end{array}$ & $\begin{array}{l}34.48 \\
33.87\end{array}$ & $\begin{array}{l}4.59 \\
4.44\end{array}$ & $\begin{array}{l}12.26 \\
11.90\end{array}$ & $\begin{array}{l}48.66 \\
47.95\end{array}$ & 92.0 \\
\hline$P_{\mathrm{s}}[6, \mathrm{Ar}]$ & 0.054 & $1 / 1$ & 24 & 99.0 & $\begin{array}{l}\text { Calcd } \\
\text { Found }\end{array}$ & $\begin{array}{l}35.82 \\
35.50\end{array}$ & $\begin{array}{l}4.85 \\
4.49\end{array}$ & $\begin{array}{l}11.94 \\
11.75\end{array}$ & $\begin{array}{l}47.39 \\
46.75\end{array}$ & 94.5 \\
\hline$P_{\mathrm{s}}[10, \mathrm{Ar}]$ & 0.040 & $1 / 1$ & 20 & 97.5 & $\begin{array}{l}\text { Calcd } \\
\text { Found }\end{array}$ & $\begin{array}{l}40.54 \\
40.07\end{array}$ & $\begin{array}{l}5.74 \\
5.44\end{array}$ & $\begin{array}{l}10.81 \\
10.62\end{array}$ & $\begin{array}{l}42.91 \\
42.10\end{array}$ & 94.0 \\
\hline
\end{tabular}

a Reaction was carried out at the boiling point of solvents $\mathrm{CH}_{3} \mathrm{NO}_{2} / \mathrm{CHCl}_{3}$.

were obtained by phase-transfer catalyzed polycondensation of 1,4-bis(dibromomethyl)benzene and dithiols in a water solution of potassium hydroxide according to the method described by Imai et al. ${ }^{20}$ and used in our previous works. ${ }^{18,19}$ Reaction conditions, reaction yield and molecular weights as well as the results of elemental analysis of obtained polysulfides are presented in Table I. The IR spectra of these polysulfides show that these polymers are free from dithiols (lack of absorption at $2550 \mathrm{~cm}^{-1}$ corresponding to $-\mathrm{SH}$ group. The polycations were prepared by methylation of sulfur atoms in polysulfides using methyl iodide. The degree of substitution of sulfur atoms was determined by titration of 
iodine anions by Mohr's method. ${ }^{21}$ Reaction conditions, reaction yield, degree of methylation and the results of elemental analysis are presented together in Table II.

\section{Synthesis of TCNQ Salts}

The polymeric TCNQ simple salts of polycations were obtained by a reaction of polycations $P_{\mathrm{s}}[x, \mathrm{Ar}]$ with LiTCNQ in a water-methanol mixture at room temperature, by a method similar to that in our previous papers. ${ }^{18,19}$ These products were identified by electronic and IR spectra. The lack of $\mathrm{TCNQ}^{\circ}$ in simple salts was estimated from electronic absorption spectra obtained with a Unicam SP-1700 spectrometer. Since all these spectra are similar, we present here only the ratio of the characteristic absorption bands $A_{1} / A_{2}$ at $\lambda_{1}=$ $420 \mathrm{~nm}$ and $\lambda_{2}=842 \mathrm{~nm}$ as follows:

$$
\begin{array}{ll}
K_{\mathrm{s}}{ }^{\prime}(3, \mathrm{Ar}) ; & A_{1} / A_{2}=0.580 \\
K_{\mathrm{s}}{ }^{\prime}(4, \mathrm{Ar}) ; & A_{1} / A_{2}=0.575 \\
K_{\mathrm{s}}{ }^{\prime}(5, \mathrm{Ar}) ; & A_{1} / A_{2}=0.570 \\
K_{\mathrm{s}}{ }^{\prime}(6, \mathrm{Ar}) ; & A_{1} / A_{2}=0.576 \\
K_{\mathrm{s}}{ }^{\prime}(10, \mathrm{Ar}) ; & A_{1} / A_{2}=0.575
\end{array}
$$

The ratio $A_{1} / A_{2} \approx 0.57$, according to the results of Rembaumetal., ${ }^{9}$ corresponds to simple salts. Complexes salts were prepared by a one-stage method on a mixture of acetonitrile and ethanol $(4: 1$ by volume) using the reagent ratio $1: 2: 1$ (polycation-LiTCNQ-TCNQ ${ }^{\circ}$ ). The molar ratio $\left.\left[\mathrm{TCNQ}^{\circ}\right] / \mathrm{TCNQ}^{-}\right]$in complex TCNQ salts was determined from the relations ${ }^{22}$ :

$$
\begin{aligned}
{\left[\mathrm{TCNQ}^{-}\right]=} & \frac{A_{744}}{\varepsilon_{744\left(\mathrm{TCNQ}^{-}\right)}} \\
{\left[\mathrm{TCNQ}^{\circ}\right]=} & \frac{A_{394}-\varepsilon_{394\left(\mathrm{TCNQ}^{-}\right)}\left[\mathrm{TCNQ}^{-}\right]}{\varepsilon_{394\left(\mathrm{TCNQ}^{\circ}\right)}} \\
= & \left\{\varepsilon_{744\left(\mathrm{TCNQ}^{-}\right)} \cdot A_{394}-\varepsilon_{394\left(\mathrm{TCNO}^{-}\right)} \cdot A_{744}\right\} \\
& \times\left\{\varepsilon_{394\left(\mathrm{TCNQ}^{\circ}\right)} \cdot \varepsilon_{744\left(\mathrm{TCNQ}^{-}\right)}\right\}^{-1}
\end{aligned}
$$

where $\varepsilon_{394\left(\mathrm{TCNQ}^{-}\right)}$and $\varepsilon_{744\left(\mathrm{TCNQ}^{-}\right)}$are the molar absorption coefficients of TCNQ $^{-}$at $\lambda=394 \mathrm{~nm}$ and $744 \mathrm{~nm}$, respectively and $\varepsilon_{394\left(\mathrm{TCNQ}^{\circ}\right)}$ is the molar absorption coefficient of $\mathrm{TCNQ}^{\circ}$ at $\lambda=$

\begin{tabular}{|c|c|c|c|c|}
\hline \multirow{2}{*}{ Symbol } & \multirow{2}{*}{$\frac{\text { Solvent }}{\mathrm{M}_{2} \mathrm{O} / \mathrm{CH}_{3} \mathrm{OH}}$} & \multirow{2}{*}{$\begin{array}{c}\begin{array}{c}\text { Ionene } \\
\text { concentration }\end{array} \\
\text { moll }^{-1}\end{array}$} & \multirow{2}{*}{$\begin{array}{c}\begin{array}{c}\text { Yield of } \\
\text { simple salt }\end{array} \\
\%\end{array}$} & \multirow{2}{*}{$\begin{array}{c}\begin{array}{c}\text { Yield of } \\
\text { complex salt }\end{array} \\
\%\end{array}$} \\
\hline & & & & \\
\hline $\begin{array}{l}K_{\mathrm{s}}^{\prime}[3, \mathrm{Ar}] \\
K_{\mathrm{s}}[3, \mathrm{Ar}]\end{array}$ & $1 / 7$ & 0.10 & 75.0 & 47.0 \\
\hline $\begin{array}{l}K_{\mathrm{s}}^{\prime}[4, \mathrm{Ar}] \\
K_{\mathrm{s}}[4, \mathrm{Ar}]\end{array}$ & $1 / 7$ & 0.10 & 78.0 & 45.0 \\
\hline $\begin{array}{l}K_{\mathrm{s}}^{\prime}[5, \mathrm{Ar}] \\
K_{\mathrm{s}}[5, \mathrm{Ar}]\end{array}$ & $1 / 10$ & 0.66 & 71.0 & 45.5 \\
\hline $\begin{array}{l}K_{\mathrm{s}}^{\prime}[6, \mathrm{Ar}] \\
K_{\mathrm{s}}[6, \mathrm{Ar}]\end{array}$ & $1 / 10$ & 0.66 & 69.5 & 49.0 \\
\hline $\begin{array}{l}K_{\mathrm{s}}{ }^{\prime}[10, \mathrm{Ar}] \\
K_{\mathrm{s}}[10, \mathrm{Ar}]\end{array}$ & $1 / 7$ & 0.10 & 75.0 & 42.5 \\
\hline
\end{tabular}
$394 \mathrm{~nm}$. Molar absorption coefficients of these compounds are taken from the work of Mizoguchi et $a .^{22}$ Reaction conditions and yields of simple and complex salts formations are given in Table III. The results of elemental analysis show a complete substitution of iodine anions $\left(\mathrm{I}^{-}\right)$on anion radicals $\left(\mathrm{TCNQ}^{-}\right)$. In further discussions, the

Table III. Synthesis of macromolecular simple ${ }^{a}$ and complex ${ }^{b}$ salts of TCNQ

${ }^{\mathrm{a}}[\mathrm{LiTCNQ}] /[$ Polycation $]=2.0$ at room temperature for $1 \mathrm{~h}$.

b $[\mathrm{LiTCNQ}] /\left[\right.$ Polycation]/[TCNQ ${ }^{\circ}=2: 1: 1$ at the boiling point of the solvents: acetonitryl-ethanol $(4: 1$ by volume) for $1 \mathrm{~h}$. 
following abreviation are used $K_{\mathrm{s}}{ }^{\prime}[x, \mathrm{Ar}]$ for simple salts of polycations and $P_{\mathrm{s}}[x, \mathrm{Ar}]$ and $K_{\mathrm{s}}[x, \mathrm{Ar}]$ for complex salts of these polycations respectively.

\section{Measurement of Electrical Properties}

The electrical property characterization of simple and complex salts was made using $1 \mathrm{~mm}$ thick pellets from polycrystalline substances prepared under pressure $10000 \mathrm{kG} \mathrm{cm}^{-2}$ in the absence of air. Vacuum deposited gold electrodes ensured good electrical contact. The specific resistivity values $\rho$ and thermal activation energy values $\left(E_{\mathrm{a}}\right)$ were calculated from current-voltage characteristics measured in vacuum at different temperature $(150$ $330 \mathrm{~K})$.

\section{RESULTS AND DISCUSSION}

The influence of $\mathrm{TCNQ}^{\circ}$ content on $\rho$ and $E_{\mathrm{a}}$ values is similar to that observed for TCNQ salts of polycations containing $\mathrm{S}^{+}$atoms in the main chain (without aromatic groups) i.e. the specific resistivities and activation energy are lowest when $\mathrm{TCNQ}^{\circ} / \mathrm{TCNQ}^{-}=1 .{ }^{18,19}$ The determined $\rho$ and $E_{\mathrm{a}}$ values for simple and complex salts are shown in Table IV. The plots of $\log \rho v s .1 / T$ for simple salts show a break at a temperature of about $200 \mathrm{~K}$. Below this temperature, lower $E_{\mathrm{a}}$ values were found. The only exception was the simple salt $K_{\mathrm{s}}{ }^{\prime}[10, \mathrm{Ar}]$ for which this break occurs at a higher temperature (Figure 1). For complex salts this break point could not be detected particularly when the $\mathrm{TCNQ}^{\circ} / \mathrm{TCNQ}^{-}$ratio was equal to one. It is interesting to note that the increase $\mathrm{TCNQ}^{\circ} \%$ $\mathrm{TCNQ}^{-}$ratio from 0.1 to 1.0 results in the disappearance of the break point as shown in Figures 2

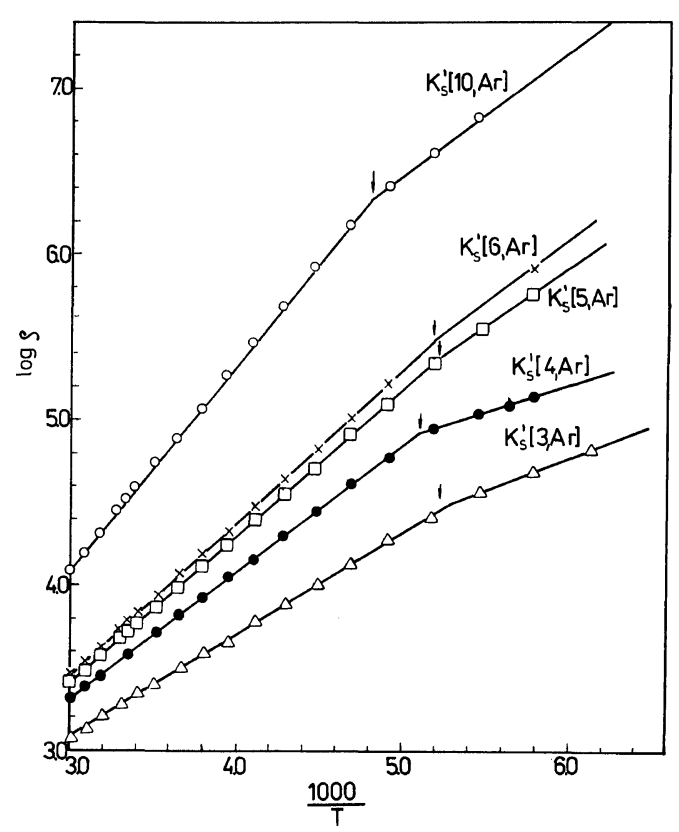

Figure 1. Dependence of $\log \rho$ on $1000 / T$ for simple TCNQ salts.

Table IV. Specific resistivities $\rho^{\mathbf{a}}$ and thermal activation energies

$E_{\mathrm{a}}$ of the electrical conductivities of TCNQ salts

\begin{tabular}{|c|c|c|c|c|c|c|c|c|}
\hline \multirow{3}{*}{$\begin{array}{c}\text { TCNQ } \\
\text { salts }\end{array}$} & \multicolumn{4}{|c|}{ Simple salts } & \multicolumn{4}{|c|}{ Complex salts } \\
\hline & \multirow{2}{*}{$\frac{\rho}{\Omega \mathrm{cm}^{-1}}$} & \multicolumn{2}{|c|}{$E_{\mathrm{a}} / \mathrm{eV}$} & \multirow{2}{*}{$\frac{T_{\mathrm{p}}}{{ }^{\circ} \mathrm{C}}$} & \multirow{2}{*}{$\frac{\left[\mathrm{TCNQ}^{\circ}\right]}{\left[\mathrm{TCNQ}^{\top}\right]}$} & \multirow{2}{*}{$\frac{\lambda_{842}}{\lambda_{394}}$} & \multirow{2}{*}{$\frac{\rho \min }{\Omega \mathrm{cm}^{-1}}$} & \multirow{2}{*}{$\frac{E_{\mathrm{a}}}{\mathrm{eV}}$} \\
\hline & & $T>T_{\mathrm{p}}$ & $T<T_{\mathrm{p}}$ & & & & & \\
\hline$K_{\mathrm{s}}[3, \mathrm{Ar}]$ & $2.16 \times 10^{3}$ & 0.120 & 0.072 & -84 & 0.9 & 1.97 & 9.30 & 0.030 \\
\hline$K_{\mathrm{s}}[4, \mathrm{Ar}]$ & $3.79 \times 10^{3}$ & 0.153 & 0.062 & -77 & 1.0 & 2.20 & 6.22 & 0.026 \\
\hline$K_{\mathrm{s}}[5, \mathrm{Ar}]$ & $5.14 \times 10^{3}$ & 0.175 & 0.127 & -82 & 1.0 & 2.30 & 3.45 & 0.023 \\
\hline$K_{\mathrm{s}}[6, \mathrm{Ar}]$ & $5.98 \times 10^{3}$ & 0.188 & 0.134 & -80 & 1.0 & 2.18 & 3.11 & 0.021 \\
\hline$K_{\mathrm{s}}[10, \mathrm{Ar}]$ & $3.28 \times 10^{4}$ & 0.250 & 0.146 & -65 & 0.8 & 1.85 & 60.0 & 0.032 \\
\hline
\end{tabular}

a $\rho$ values at $25^{\circ} \mathrm{C}$. 


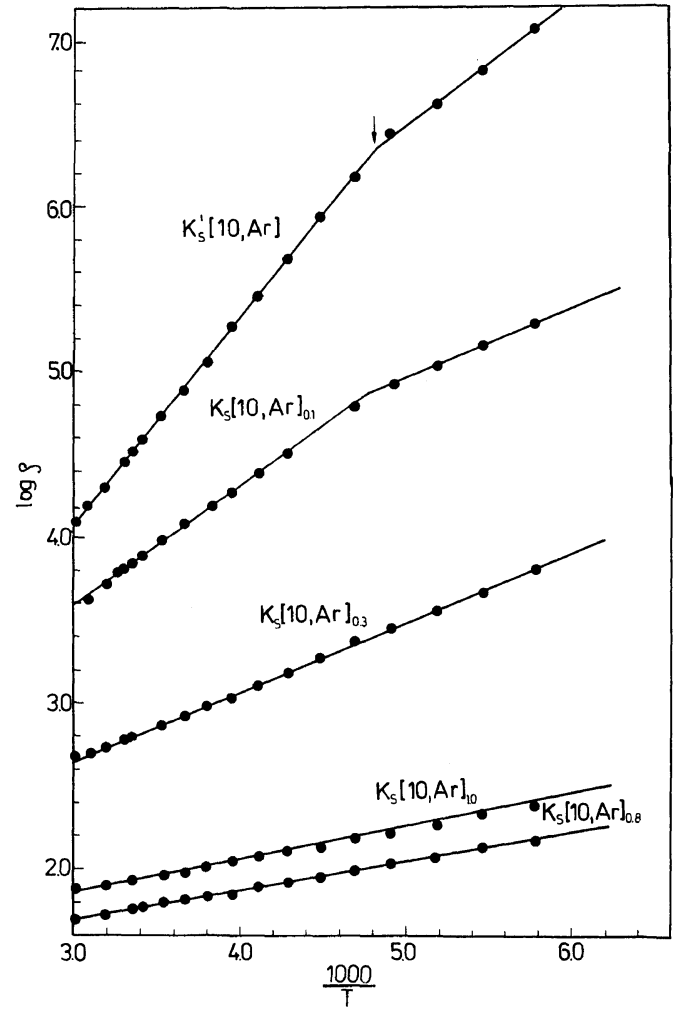

Figure 2. Dependence of $\log \rho$ on $1000 / T$ for simple TCNQ salts $K_{\mathrm{s}}{ }^{\prime}[10, \mathrm{Ar}]$ and for the complex salts $K_{\mathrm{s}}[10, \mathrm{Ar}]$ with different $\left[\mathrm{TCNQ}^{\circ}\right] /\left[\mathrm{TCNQ}^{\top}\right]$ ratios.

and 3, respectively. This behaviour suggests that the appearance of break points is related to the composition of these salts and the position of the mentioned break points on the temperature scale depends on the chemical structure of polycations. However, this effect has been noted in many papers describing the electrical properties of semiconducting polymers ${ }^{1,7,16,23,24}$ and is ascribed to impurities, occlusion of oxygen, and glass transition phenomena. The break points were observed both for samples investigated in air and in a vacuum. Thus, the role of oxygen occlusions in the above mentioned effect must be excluded. It seems that the most probable cause for the appearance of break points is the presence of a noncrystalline material. This is supported by the well known observation of break points for all simple salts (Figure 1) characteristic of lower crystallinity compared with complex salts.

The $\rho$ and $E_{\mathrm{a}}$ values decrease with the con-

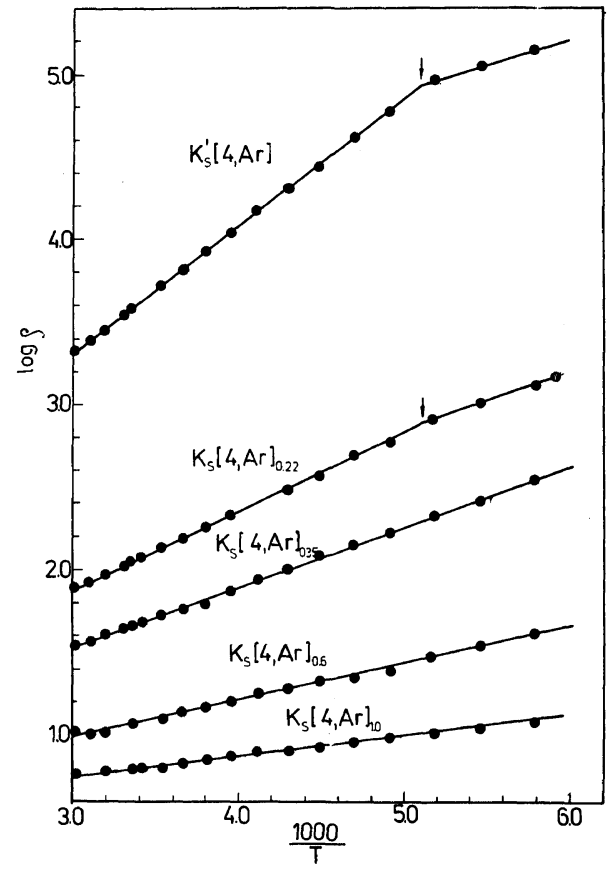

Figure 3. Dependence of $\log \rho$ on $1000 / T$ for the simple salt $K_{\mathrm{s}}[4, \mathrm{Ar}]$ and for the complex salts $K_{\mathrm{s}}[4$, Ar] with different $\left[\mathrm{TCNQ}^{\circ} / /\left[\mathrm{TCNQ}^{-}\right]\right.$ratios.

centration of neutral $\mathrm{TCNQ}^{\circ}$ and the complexes for which $\mathrm{TCNQ}^{\circ} / \mathrm{TCNQ}^{-} \approx 1$ show a resistivity three orders of magnitude lower than the corresponding simple salts (see $K_{s}[4, \mathrm{Ar}], K_{s}[5, \mathrm{Ar}]$, and $K_{s}[6, \mathrm{Ar}]$ ). But for $\mathrm{TCNQ}^{\circ} / \mathrm{TCNQ}^{-}=0.9$ or 0.8 the lowest $\rho$ and $E_{\mathrm{a}}$ values were found for $K_{\mathrm{s}}[3, \mathrm{Ar}]$ and $K_{\mathrm{s}}[10, \mathrm{Ar}]$, respectively. This suggests that the $\mathrm{TCNQ}^{\circ}$ molecules are associated with polycations forming a stack of alternating charged and neutral $\mathrm{TCNQ}^{\circ}$ molecules in analogy to other high and low molecular weight cations. ${ }^{5,10,11}$ The noncomplete electron transfer in the stacks leads to stabilization of the crystalline structure, a decrease in repulsion between $\mathrm{TCNQ}^{-}$molecules and thus to a decrease in thermal activation energy of conductivity. The packing of $\mathrm{TCNQ}^{-}$and $\mathrm{TCNQ}^{\circ}$ molecules depends on the distance between the charged $\mathrm{S}^{+}$atoms. Thus the complex salts $K_{\mathrm{s}}[10, \mathrm{Ar}]$ show higher resistivity and activation energy compared with all other complex salts as in the case of complex salts containing $\mathrm{CH}_{2}$ groups between positively charged $\mathrm{S}^{+}$atoms. ${ }^{18}$ For the complex $K_{\mathrm{s}}[3, \mathrm{Ar}]$ the lowest resistivities correspond to $\mathrm{TCNQ}^{\circ} / \mathrm{TCNQ}^{-}=0.9$ 


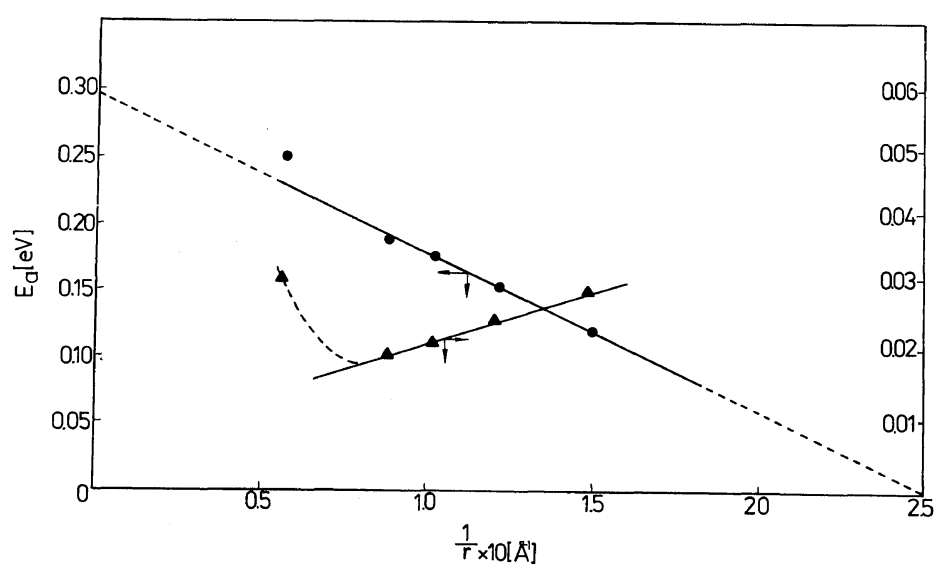

Figure 4. Dependence of activation energy $E_{\mathrm{a}}$ on reciprocal distance between donor centres in simple salts $K_{\mathrm{s}}{ }^{\prime}[x, \mathrm{Ar}]$ and complex salts $K_{\mathrm{s}}[x, \mathrm{Ar}]$.

since the small distance between $\mathrm{S}^{+}$atoms (three $\mathrm{CH}_{2}$ groups) does not allow for proper packing of TCNQ molecules. The lowest $\rho$ value $(\rho=3.11 \Omega \mathrm{cm})$ found for $K_{\mathrm{s}}[6, \mathrm{Ar}]$ is still smaller than that found for complex salts with six methylene groups between $\mathrm{S}^{+}$atoms ${ }^{19}$; however, the $E_{\mathrm{a}}$ value is somehow higher compared to corresponding $K_{\mathrm{s}}[x, y]$ complexes, $\left(K_{\mathrm{s}}[x, y]\right.$ is the TCNQ complex salt of $x, y$-ionenes). This may possibly be related to higher crystallinity and intergranular barriers. The incorporation of stiffer segments into polycation chains, as $a$ with the compounds discussed in ref 13 , causes a decrease in resistivity. The results provide some understanding of the influence of the distance between $\mathrm{S}^{+}$atoms on the conductivity of obtained polymers. Figure 4 shows the dependence of $E_{\mathrm{a}}$ values on the reciprocal of the distance between the donor centers in polycations $P_{\mathrm{s}}[x, \mathrm{Ar}]$. The $r$ values were calculated taking into consideration the bond lengths and angles of the given polycation $P_{\mathrm{s}}[x, \mathrm{Ar}]$. In both cases, a linear decrease in activation energy was found. The lowest value $E_{\mathrm{a}}=0.12 \mathrm{eV}$ corresponded to $K_{\mathrm{s}}{ }^{\prime}[3, \mathrm{Ar}]$ and $E_{\mathrm{a}}=$ $0.021 \mathrm{eV}$ to $K_{\mathrm{s}}[6, \mathrm{Ar}]$. For both simple and complex salts, the deviation from a linear relation was found for $P_{\mathrm{s}}[10, \mathrm{Ar}]$; this may be related to the less effective packing of TCNQ molecules. It seems interesting to note that there is a linear relationship between $\log \rho$ and $E_{\mathrm{a}}$ both for the simple and complex salts of TCNQ (Figures 5 and 6). Such dependence was not established for polycations containing $\mathrm{N}^{+}$atoms in the main chain, ${ }^{13}$

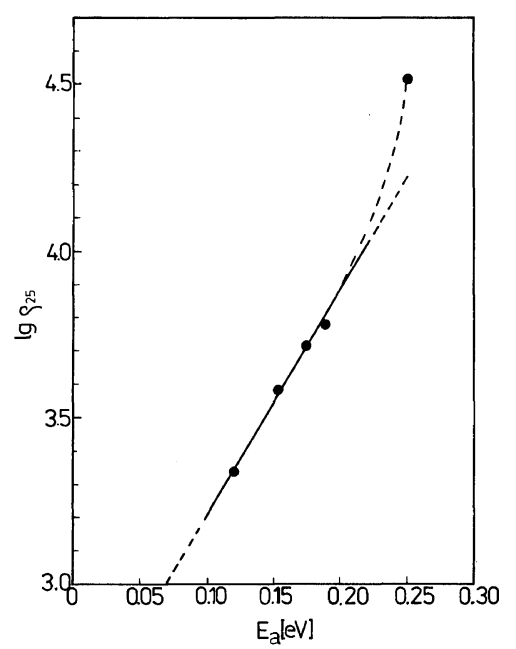

Figure 5. The plot of $\log \rho$ vs. $E_{\mathrm{a}}$ for simple salts $K_{\mathrm{s}}{ }^{\prime}[x, \mathrm{Ar}]$.

but was observed for polycations with cyclohexyl rings in the main chain. ${ }^{27}$ The important difference between the resistivity of simple and complex TCNQ salts can be elucidated by taking into consideration the transfer of an electron between two $\mathrm{TCNQ}^{-}$molecules and a $\mathrm{TCNQ}^{-}-\mathrm{TCNQ}^{\circ}$ pair. In the case of simple and complex TCNQ salts of polycations containing $\mathrm{S}^{+}, \mathrm{CH}_{2}$ groups and aromatic groups, an argumentation similar to that in ref 19 is valid and is based on the dependence of $E_{\mathrm{a}}$ values on coulombic repulsions $C$ and band with $\Delta$ proposed by the Le Blanc. ${ }^{28}$ This 


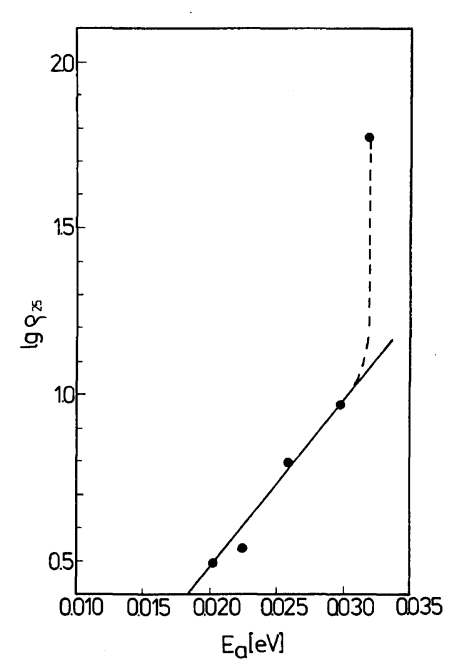

Figure 6. The plot of $\log \rho$ vs. $E_{\mathrm{a}}$ for complex salts $K_{\mathrm{s}}[x, \mathrm{Ar}]$.

reasoning leads to the conclusion that not only the distance between the charged centers and thus between the TCNQ molecules ${ }^{29}$ but also on the polarizability of the cation is of importance. ${ }^{28,30,31}$ For simple salts $K_{\mathrm{s}}{ }^{\prime}[x, \mathrm{Ar}], E_{\mathrm{a}}$ values depend mostly on the electrostatic energy $C$ which decreases with a decrease in the distance between the $\mathrm{S}^{+}$atoms (see Figure 4). For complex salts $K_{\mathrm{s}}[x, \mathrm{Ar}]$ the resistivity decreases until $\mathrm{TCNQ}^{\circ} / \mathrm{TCNQ}^{-}$reaches a value close to one (see ref $10,12,19$ ) and because the proper distance between TCNQ molecules results in a greater overlapping of $\pi$ orbitals the bandwidth $\Delta$ increases. In this case, the activation energy takes on lower values except for $K_{\mathrm{s}}[3, \mathrm{Ar}]$ and $K_{\mathrm{s}}[10, \mathrm{Ar}]$ complexes for which the distances between $\mathrm{S}^{+}$are either small (three $\mathrm{CH}_{2}$ groups) or too big $\left(10 \mathrm{CH}_{2}\right.$ groups). Consequently, the activation energies are higher than those of other complexes. It is reasonable to expect that optimal values can be obtained for the distance between $\mathrm{S}^{+}$atoms which results in minimal $C$ values and maximal bandwidths $\Delta$. This is the case for the complex $K_{\mathrm{s}}[6, \mathrm{Ar}]$. It was proposed that when $C=0.5-1 \mathrm{eV}$ and $\Delta$ about $0.1 \mathrm{eV},{ }^{29}$ a very small activation energy values should arise from another factor, the polarizability of cation. ${ }^{28,30,31}$ Le Blanc ${ }^{28}$ observed that the conductivity of complex salts tends to increase with an increase in the polarizability of the cationic component. This is consistent with the general approach used by Mott $^{32}$ and Hubbard ${ }^{33}$ to describe con- duction in narrow-band systems where the electron correlation energies approach or exceed the band width of conduction states. The high polarizability of aromatic cations is an effective factor for decreasing coulombic repulsions and in lowering the activation energy. In a very favourable case when bandwidth is large, the coulombic repulsion may be neglected and metallic conductivity may be expected. ${ }^{30}$ Polarizability values of the cations used are not known directly but can be estimated from known quantities such as the longest wavelength $\lambda_{\max }$ of the $\pi-\pi^{*}$ transitions. Klanderman et al. ${ }^{34}$ have estimated the $\lambda$ values for several cations and then the conductivity $\sigma_{300}$ and $E_{\mathrm{a}}(\mathrm{eV})$ for TCNQ salts with these cations. They found that an increase in $\lambda_{\max }$ and consequence by in polarizability, results in an increase in the specific conductivity of TCNQ salts and in a decrease in, the activation energy of electrical conductivity.

The substitution of nitrogen by sulfur in some compounds causes an increase in conductivity. Kamiya et al..$^{35}$ have investigated the effect of cations and polycations on the conductivity of TCNQ salts, taking into consideration the influence of steric effects on polarizability. It seems reasonable to conclude that the introduction of sulfur atoms in place of nitrogen atoms in polycation chains results in an increase in polarizability. This effect is responsible for the lower resistivity and activation energy values of the investigated TCNQ salts as compared with those containing $\mathrm{N}^{+}$centers in the main chain. ${ }^{13}$

Studies on the magnetic properties and crystallinity of these TCNQ salts will provide a clearer understanding of the findings presented above.

\section{CONCLUSIONS}

Complex salts of TCNQ with polycations containing sulfur atoms in the main chain as well as stiffer aromatic segments show high electrical conductivity and low thermal activation energy of conductivity. The electrical properties of these complexes depend on the distance of the $\mathrm{S}^{+}$donor centers. For complex TCNQ salts of these polycations, the $E_{\mathrm{a}}$ values decrease linearly with the distance between $\mathrm{S}^{+}$atoms this is related to the better packing of $\mathrm{TCNQ}^{\circ}$ and $\mathrm{TCNQ}^{-}$molecules. The increase in conductivity of simple and complex TCNQ salts of the investigated polycations com- 


\section{J. PeCherz and M. KRyszewsKi}

pared with those containing charged nitrogen centers is related to the higher polarizability of sulfur atoms. This causes a reduction in coulombic repulsions. Further studies on the magnetic properties of these complex TCNQ salts will provide more quantitative information on the structural influence on the physical properties of these conducting organic polymers.

\section{REFERENCES}

1. M. Kryszewski, "Semiconducting Polymers PWN," Polish Scientific Publishers, Warsaw, 1980.

2. J. H. Lupiński, K. D. Kopple, and J. J. Hertz, J. Polym. Sci., 16, 1561 (1967).

3. A. Rembaum, W. Baumgartner, and A. Eisenberg, $J$. Polym. Sci., B, 6, 159 (1980).

4. A. Rembaum, J. Macromol. Sci. Chem., A3, 87 (1969).

5. Y. Hadek, H. Noguchi, and A. Rembaum, Macromolecules, 4, 494 (1971).

6. Y. Hadek, H. Noguchi, and A. Rembaum, Polym. Prep., Am. Chem. Soc., Div. Polym. Chem., 12, 90 (1971).

7. W. Ciesielski and M. Kryszewski, Ann. Soc. Chim. Polonorum, 50, 947 (1976).

8. S. Ikeno, K. Matsumoto, M. Yokoyama, and H. Mikawa, Polym. J., 9, 261 (1977).

9. A. Rembaum, A. J. Hermann, F. E. Stewart, and F. Gutman, J. Phys. Chem., 73, 513 (1969).

10. T. Kamiya, K. Goto, and I. Shinohara, J. Polym. Sci., Polym. Chem. Ed., 17, 561 (1979).

11. A. Blumstein and G. Weill, Macromolecules, 10, 75 (1977).

12. T. Kamiya and I. Shinohara, J. Polym. Sci., Polym. Lett. Ed., 17, 641 (1979).

13. W. Ciesielski, J. Pecherz, and M. Kryszewski, Acta Polymerica., 33, 318 (1982).

14. K. Mizoguchi, S. Kajiura, A. Nakano, F. Tsuchida, and I. Shinohara, Nippon Kagaku Kaishi, 8, 1404 (1975).

15. K. Mizoguchi, H. Togou, E. Tsuchida, and I.
Shinohara, Nippon Kagaku Kaishi, 12, 2211 (1975).

16. W. Ciesielski and M. Kryszewski, Ann. Soc. Chim. Polonorum, 50, 1159 (1976).

17. I. F. Shechegolev, Phys. Status Solid. A, 12, 9 (1972).

18. J. Pecherz, W. Ciesielski, and M. Kryszewski, Macromolecules, 14, 1139 (1981).

19. J. Pecherz and M. Kryszewski, Acta Polymerica, 34, 19 (1983).

20. Y. Imai, A. Kato, M. Ii, and M. Ueda, J. Polym. Sci., Polym. Lett. Ed., 17, 579 (1979).

21. W. C. Pierce, E. L. Haenisch, and D. T. Sawyer, "Quantitative Analysis," Wiley, New York, 1963, p 320.

22. K. Mizoguchi, S. Tsuji, E. Tsuchida, and I. Shinohara, J. Polym. Sic., Polym. Chem. Ed., 16, 3259 (1978).

23. Ya. M. Paushkin, T. P. Vishnyakova, A. F. Lunin, and S. A. Nizova, "Organic Polymeric Semiconductors," John Wiley and Sons, New York, N. Y., 1974.

24. S. Saito, H. Sasabe, and T. Nakajima, J. Polym. Sci., A, 2, 1297 (1968).

25. I. I. Ukrainskii, V. E. Klymenko, and A. A. Ovchinnikow, J. Phys. Chem. Solids, 39, 359 (1978).

26. E. M. Engler, Chem. Technol., 6, 274 (1976).

27. K. Mizoguchi, S. Kajiura, A. Nakano, E. Tsuchida, and I. Shinohara, Nippon Kagaku Kaishi, 8, 1404 (1975).

28. O. H. Le Blanc, J. Chem. Phys., 42, 4307 (1965).

29. A. F. Garito and A. H. Heeger, Acc. Chem. Res., 7, 232 (1974).

30. A. J. Epstein, S. Etemand, A. F. Garito, and A. J. Heeger, Phys. Rev., B5, 952 (1972).

31. L. B. Coleman, J. A. Cohen, A. F. Garito, and A. J. Heeger, Phys. Rev., B7, 2122 (1973).

32. N. F. Mott, Phil. Mag., 6, 287 (1961).

33. J. Hubbard, Proc. R. Soc. London, Ser. A, 285, 542 (1965).

34. B. H. Klanderman and D. C. Hoesterey, J. Chem. Phys., 51, 377 (1969).

35. T. Kamiya, S. Tsuji, K. Ogatsu, and I. Shinohara, Polym. J., 11, 219 (1979). 